\title{
3. LICHT UND FINSTERNIS IN DER BILDPUBLIZISTIK VON 1789 BIS 1870
}

\subsection{Die Französische Revolution}

\subsubsection{Sonnenaufgang und Zeitenwende: Licht als Metapher des Neubeginns}

Das beherrschende bildliche Moment in der Revolutionsgraphik ${ }^{1}$ ist das des epochalen Wendepunktes, der immer wieder als eine Art Lichtgeburt ${ }^{2}$ dargestellt wurde. Die Zeit von 1789 bis 1794 war von der permanenten Propagierung neuer Zeitabschnitte und ständiger Neuanfänge zutiefst geprägt: Mit der Stürmung der Bastille am 14. Juli 1789 schien bereits ein neues Zeitalter begonnen zu haben, das sich auf den »Mythos einer zukunftsoffenen Neugründung Frankreichs $\aleph^{3}$ stützte. Das immer weiter ausgeschmückte Bild der schrecklichen Festung, die für die Gefangenen das Grab war, wurde zum übermächtigen Symbol für das Ancien Régime und schließlich mit diesem gleichgesetzt. Die Ereignisse des 14. Juli erscheinen als epochaler Befreiungsschlag, als Menetekel des Zeitenwandels. Den entscheidenden Moment der Wende, der goldene Zeiten heraufführen sollte, zeigt etwa die Radierung L'époque de la liberté française von $1789^{4}$. Necker verweist den im Krönungsornat gekleideten König auf die vereinten drei Stände. Im Hintergrund steht die bereits eroberte Bastille. Die Szene wird von einer immensen Lichtwolke mit dem strahlenden Dreieck im Zentrum beherrscht. Aus der Wolke ragt eine Hand mit der Fackel der Wahrheit, der nun alle folgen wollen. Die versöhnliche Aufbruchstimmung wird bald durch von drastischen Feindbildern bestimmte Szenerien ersetzt, in denen der Neuanfang unabdingbar die Zer-

1 Zur Lichtsymbolik in der Graphik der Französischen Revolution sei auf ReICHARDT, Lumières, verwiesen. Die vorliegende Zusammenfassung soll nur einige im Hinblick auf die III. Republik wichtige Aspekte herausstellen. Bildinterpretationen konzentrieren sich stark auf den Licht-Finsternis-Aspekt. Allg. zur Revolutionsgraphik vgl. Klaus Herding, Rolf Reichardt, Die Bildpublizistik der französischen Revolution, Frankfurt a. M. 1989; Ernst Gomвrich, The Dream of Reason: Symbolism of the French Revolution, in: The British Journal for Eighteenth-Century Studies 2 (1979), S. 187-205; Antoine DE BAEQUE, La caricature révolutionnaire, Paris 1988; Michel Vovelle (Hg.), Les images de la Révolution française, Actes du colloque 25-27 octobre 1985, Paris 1988.

2 Reichard, Lumières, S.130. Dazu allg. Mona Ozouf, Erneuerung, in: Kritisches Wörterbuch der Französischen Revolution, hg.v. François Furet und Mona Ozouf, 2 Bde., Frankfurt a. M. 1996, Bd.2, S. 1071-1086.

3 Reichardi, Lumières, S.160. Besonders in der deutschen Publizistik wurde die Erobe-

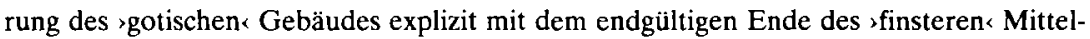
alter in Verbindung gebracht. Vgl. Jürgen LiNK, Die Revolution im System der Kollektivsymbolik. Elemente einer Grammatik interdiskursiver Ereignisse, in: Aufklärung 1, 2 (1986), bes. S. 7f.

${ }^{4}$ Radierung, 1789. BnF, Est., Coll. Hennin 10525. Herding, Reichardt, Bildpublizistik, S.113, Abb. 145. 
störung und Aburteilung des Vorherigen voraussetzt. Auf der Darstellung La Révolution française arrivée sous le règne de Louis XVI von 1792 sendet die selbst hell strahlende Wahrheit die von ihrem Spiegel reflektierten Lichtstrahlen auf einen Leichenzug, der die Insignien des Ancien Régime zu Grabe trägt ${ }^{5}$. Die Bastille, im Hintergrund noch in voller Größe und so als Denkmal für die Eroberungsleistung zu verstehen, ist auf der Vignette unter dem Bild zerstört und von den Allegorien des Ruhmes in Besitz genommen. Im Bildvordergrund ist Chronos dabei, die Zeichen der alten Macht zu zerschlagen und unterstreicht somit die Untrennbarkeit von Überwindung und Zerstörung des Alten. Zunächst untersteht natürlich auch die neue Zeit dem Zeitenlauf: Gerade in Verbindung mit der Sonnenaufgangssymbolik ist die notwendige Folge des Sonnenuntergangs - und damit des Niedergangs - immanent. Diese Grundproblematik der lumières ${ }^{6}$ mußte in der Revolution, die sich ja als Realisierung und Vergeschichtlichung des philosophisch schon Vorgedachten verstand, noch weitaus sensibler empfunden werden. Chronos ${ }^{7}$ als Verkörperung der Zeit erhält in der Bildersprache der Revolution deshalb in Verbindung mit der Lichtsymbolik die Rolle eines Vollenders von Zeit und Geschichte, »ihm fällt die Rolle zu, die Entwicklung als unumkehrbar hinzustellen, also Zeitlosigkeit zu suggerieren $\aleph^{8}$.

Diese Fähigkeit wurde auch von den Gegnern der Revolution in Anspruch genommen: Aus dem Frühjahr 1792 datiert ein Blatt mit dem Titel Le Crible de la Révolution'. Darauf hat Chronos seine Sense, sein Stundenglas sowie eine entzündete Fackel auf dem Boden abgelegt, um ein großes Sieb zu rütteln. Während die Büsten mehrerer Verfechter der Revolution, darunter auch Philippe d'Orléans, bereits zu Boden gefallen sind, hat die königliche Familie die Probe bestanden. Chronos fungiert dabei als Vollstrecker eines feststehenden Gesetzes: Das Sieb ist an einem Gerüst aus drei Stäben aufgehängt, die

\footnotetext{
5 Aquatintaradierung, 1792. BnF., Est., Coll. de Vinck 1702. Herding, Reichard, Bildpublizistik, S.92f., Abb.123. Vollständige Wiedergabe der Legende in: Gérard OBERLÉ u. a. (Hg.), Rue de la Révolution. Images populaires de la Révolution française: faïences et estampes, Nevers 1989, Bd.3, S.64f. Zum bildpublizistischen Schicksal Ludwigs XVI. vgl. Annie Duprat, Le roi décapité. Essai sur les imaginaires politiques, Paris 1992.

6 Vgl. auch Hans-Wolf JäGER, Politische Metaphorik im Jakobinismus und im Vormärz, Stuttgart 1971, S.119: "Die astronomischen Abläufe können weitergedacht werden, und es entstehen dann die reaktionären Kreislauftheorien von Werden und Vergehen und Werden und die zyklischen Modelle von Aufstieg, Blüte, Niedergang und Neubeginn. Durch Komplettierung der tageszeitlichen Ablösung von Nacht und Morgen [...] werden die positiven Bilder von Morgen und Frühling ihres utopischen und revolutionären Impetus beraubt«.

7 Dazu ausführlich Klaus Herding, Die Zeit im Umbruch der Zeiten, in: Idea 8 (1989), S. 95-112. Allg. dazu auch Fischer, Wer löscht das Licht, S. 24-26.

8 Herding, Zeit, S. $104 \mathrm{f}$.

9 Aquatintaradierung, 1792. BnF, Est., Coll. de Vinck 5480. Zu den etwa 150 überlieferten royalistischen Karikaturen der Französischen Revolution vgl. Claude LaNGLoIs, La caricature contre-révolutionnaire, Paris 1989. Zu Le Crible de la Révolution vgl. ibid., S. 152f., sowie S.243, Kat. 82.
} 
mit Symbolen der traditionellen Ständegesellschaft - Ritterhelm und Schwert, Bischofsmitra sowie Spaten bekrönt sind. Darum herum windet sich eine Schlange, die als Oroborossymbol den Ewigkeitsanspruch dieses Modells verdeutlichen soll. Die Möglichkeit einer Revolution ist damit von vorneherein ausgeschlossen - diese richtet sich vielmehr selbst, da sie dem göttlich vorbestimmten Zeitenlauf zu trotzen versucht. Die am Horizont aufsteigende Sonne holt auch das Symbol des Anfangs in dieses System herein, das nun von Ballast befreit und gestärkt unter den alten Prämissen neu beginnen kann.

Die Instrumentalisierung und letztendliche Aufhebung der Zeit betrifft stets unmittelbar die Naturgesetze - und damit die Natur selbst. Exemplarisch für die Vereinigung von Zeit und Natur im Dienst der Revolution ist das Blatt Le Nouvel Astre français, entstanden $1793^{10}$. Unter einer Sonnen-Kokarde, deren weit reichende Strahlen die finsteren Wolken vertreiben, ist Chronos damit beschäftigt, an den in einem Kreis aufgesteliten Büsten verschiedener Monarchen die Kerzen auszulöschen. Hier volizieht sich zunächst eine Trennung von Herrscherfigur und Sonnensymbolik, die in ihrer Tragweite kaum zu überschätzen ist. Als Garantin des lebensspendenden Lichts war die Sonne seit der Antike das zentrale Symbol des autokratischen Herrschaftsverständnisses, das sich zudem an den Attributen der Allsichtigkeit des Sonnenauges und der daraus resultierenden Omnipräsenz orientierte ${ }^{11}$. Die Entfremdung von der Sonne erteilt somit dem vor allem in Louis XIV. als Roi-Soleil kulminierten Selbstverständnis des absoluten Monarchen eine vernichtende Absage ${ }^{12}$. Damit ist

10 Aquatintaradierung, 1793. BnF, Est., Coll. Hennin 11338. Herding, ReICHardt, Bildpublizistik, S.127, Abb.170. Dazu Klaus Herding, Visuelle Zeichensysteme in der Graphik der Französischen Revolution, in: Ders. (Hg), Im Zeichen der Aufklärung, Frankfurt a.M., S.96-103 (vollständige Interpretation); Herding, Zeit, S.98f.; Raimund RütTEN, Das Schauspiel Le Jugement dernier des rois von Sylvain Maréchal und die neue Bildlichkeit, in: Kritische Berichte 17/4 (1989), S.17-19; Fischer, Wer löscht das Licht, S.21-24; ReichaRd, Lumières, S. 129.

$11 \mathrm{Zu}$ den Wurzeln der herrschergebundenen Sonnensymbolik vgl. Mircea Eliade, Die Religionen und das Heilige, Frankfurt a.M. 1986, S.149-180. Der römische Sol Invictus war seit Aurelian der oberste Staatsgott, der als Dominus imperii romani die kaiserliche Zentralisierungspolitik verkörperte und unterstützte. Vgl. Gaston H. HALSBERGHE, The Cult of Sol Invictus, Leiden 1972, S.141-152. Das Fortleben antiker Sonnenkulte im Christentum belegt die seit 354 bezeugte Verlegung des Weihnachtsfestes auf den 25. Dezember, den heidnischen Dies Natalis Solis Invicti. Dazu Hugo Rahner, Das christliche Mysterium von Sonne und Mond, in: Eranos Jahrbuch 10 (1943), S. 324. Damit wurde der Triumph Christi als der wahren Sonne, gerechtfertigt durch die alttestamentliche Bezugnahme auf die "Sonne der Gerechtigkeit “ (Mal 3, 18), endgültig vollzogen. Dazu Franz Joseph Dölger, Die Sonne der Gerechtigkeit und der Schwarze. Eine religionsgeschichtliche Studie zum Taufgelöbnis, Münster ${ }^{2} 1971$, S. 109. Zu diesem Motiv vgl. auch Francesca Rigorti, Il sole della giustizia. Sole e luce quali metafore del vero e del giusto, in: Ders., Pierangelo Schiera (Hg), Aria, terra, aqua, fuoco. I quattro elementi e i loro metafore, Bologna 1996, S. 9-24.

12 Der Heilandscharakter, welcher der späten Geburt des Thronfolgers anhaftete und die Vorstellung des lichten Friedensbringers nach der Fronde bildeten bereits die Grundlage für die Lichtsymbolik des Königs. Vgl. Karl MösENEDER, Zeremoniell und monumentale 
die Revolution des Weltbildes aber noch nicht vollendet. Über der SonnenKokarde spannt sich ein Bogen mit den Tierkreiszeichen, der auf die untrennbare Zusammengehörigkeit beider Komponenten verweist: $\gg$ Die Kokarde folgt dem Tierkreis, d.h. das historische Emblem wird dem Lauf der Natur nachgeordnet; es verändert deren Kreislauf nicht « ${ }^{13}$.

Der seit Kopernikus geläufige, astronomische Revolutionsbegriff deckt sich hier mit dem historischen ${ }^{14}$ und ist dabei doppelt kodiert: Zum einen wird die ursprüngliche Bedeutung von Revolution als »Rückführung zum guten Alten « ${ }^{15}$ bekräftigt; angestrebt ist die Rückkehr zum Naturrecht, wie die Legende verlauten läßt: Peuples, rentrez dans vos droits.

»Daß die Zeit selbst agiert, bedeutet nichts anderes, als daß die Revolution beansprucht, den Willen der Natur zu vollstrecken und die Zeit zu serfüllen « ${ }^{16}$.

Das revolutionäre Zeitmodell greift aber noch weiter: Die von Chronos übernommene Richterfunktion bestätigt darüber hinaus die vollständige Ineinssetzung von Zeit und Fortschritt und ihre Absorption durch die revolutionäre Ideologie. Im Verständnis der lumières wurde das Vorantreiben des zivilisatorischen Fortschritts zum wichtigsten Bestandteil des Revolutions-

Poesie. Die »Entrée solennelle« Ludwigs XIV. 1660 in Paris, Berlin 1983, bes. S.32f.; Dominik Keller, Unter dem Zeichen der Sonne, in: Georg Kohler, Alice VILlon-Lechner (Hg.), Die schöne Kunst der Verschwendung. Fest und Feuerwerk in der europäischen Geschichte, Zürich, München 1988, S.57-100. Die Bezugnahme auf die Sonne zeigt sich schon in der mit einem Sonnensymbol illustrierten offiziellen Devise des Königs: Nec pluribus impar - gleich mehreren [Sonnen], die seine Qualitäten zum Ausdruck bringen sollte: "je suffirais sans doute encore à gouverner d'autres empires, comme le soleil à éclairer d'autres mondes, s'ils étaient exposés à ses rayons«.

In: LouIs XIV, Mémoires, hg. v. Jean Lognon, Paris 1978, S.136, année 1662. Auch das tägliche lever und coucher des Monarchen wurden in direkter Entsprechung zum Sonnenauf- und -untergang zelebriert. Vgl. Agnès JolY, »Le Roi-Soleik - histoire d'une image, in: Revue de l'histoire de Versailles et de Seine-et-Oise 38 (1936), S.119-135; Louis Hautecceur, Louis XIV - Roi-Soleil, Paris 1953; Ernst H. Kantorowicz, Oriens Augusti - Lever du Roi, in: Dumbarton Oaks Papers 17 (1963), S.119-177. Literarische Anklänge an den Mythos des Apoll schmückten das Bild weiter aus: Die Anlage des Schlosses und Gartens von Versailles entstand nach Metamorphosen des Sonnenpalastes - Regia Solis in Ovids Metamorphosen (II, 1-18). Dazu Jean-Marie APOsrolidès, Le roi-machine. Spectacle et politique au temps de Louis XIV, Paris 1981; Jean-Pierre NÉrAudAu, L'Olympe du Roi-Soleil. Mythologie et idéologie royale au Grand Siècle, Paris 1986. Schon die zeitgenössische protestantische Karikatur aber propagierte die ,Verdunkelung dieser königlichen Sonne, wobei besonders die Sonnenfinsternis im Mai 1706 eine wichtige Rolle spielte. Dazu Hans-Jürgen LüsebrinK, Rolf Reichardt, »Kauft schöne Bilder, Kupferstiche...«. - Illustrierte Flugblätter und französisch-deutscher Kulturtransfer 1600-1830, Mainz 1996, S.44-47; Reichardt, Lumières, S.91-96; Annie Duprat, Louis XIV: Le soleil s'éclipse, in: Ridiculosa 4 (1997), S.17-29.

${ }^{13}$ Herding, Visuelle Zeichensysteme, S. 97.

14 Ibid., S. 96.

15 Karl Griewank, Der neuzeitliche Revolutionsbegriff. Entstehung und Entwicklung, Frankfurt a. M. ${ }^{3} 1992$, S. 144.

16 Herding, Zeit, S. 99. 
begriffs ${ }^{17}$. Der Fortschritt stellt als Wiedergewinnung der Völkerrechte gleichzeitig die Rückkehr zum idealen Naturzustand dar und entzieht sich somit der Vergänglichkeit. Fortschrittsdenken und Zyklenmodell finden hier zusammen und heben die Zeit auf. Dasselbe Bedürfnis kommt im revolutionären Heldenkult zum Ausdruck: Im Pantheon kulminierte der Kult um Märtyrer des Vaterlandes in einer quasireligiösen Heldenverehrung, die den Tod und die Endlichkeit im Grunde negierte ${ }^{18}$ : Für den Tod war im Ruhmestempel als Ort der Unsterblichkeit kein Platz « ${ }^{19}$.

Unterstützt wurde der angestrebte Eindruck von Ewigkeit durch die beim Umbau des Pantheon grundlegend veränderte Lichtführung: Der Architekt Quatremère de Quincy ersetzte den ursprünglich seitlichen Lichteinfall durch ein starres, direkt von oben kommendes Licht, das den Eindruck völliger Unbeweglichkeit erwecken sollte ${ }^{20}$.

Negierung des Todes und Lichtapotheose kennzeichnen auch die bildliche Verklärung von Jean-Paul Marat, der 1793 einem Attentat der Royalistin Charlotte Corday zum Opfer fiel. Das berühmte Gemälde von Jacques Louis David hebt die realen Zeit- und Lichtverhältnisse auf zugunsten eines symbolischen Sonnenaufgangs. ${ }^{21}$ Der Tod des Revolutionshelden erhält die Aura des unsterblichen Märtyrers, dessen >Opfer $<$ die Absicht der Tat ad absurdum führt $^{22}$. Diesem Modell der Ewigkeit steht die Vergänglichkeit der widernatürlichen Herrschaft entgegen, in Le Nouvel Astre français versinnbildlicht in den Kerzen auf den Köpfen der Monarchen ${ }^{23}$. Dabei steht die Kerze als künstliches, flüchtiges Licht der naturgegebenen Leuchtkraft der Sonne direkt gegenüber, was auf einen weiteren Paradigmenwechsel in der Lichtsymbolik verweist: In der barocken Emblematik wurde der Fürst mit der Kerze verglichen, die Licht gibt und sich dabei selbst verzehrt ${ }^{24}$. Übernommen wurde dieses Bild aus der kirchlichen Symbolik, wo die Kerze für das selbstlose

17 Griewank, Revolutionsbegriff, bes. S. 166-169.

18 Martin PAPENHEIM, Erinnerung und Unsterblichkeit. Semantische Studien zum Totenkult in Frankreich (1715-1794), Stuttgart 1992, S. 284-296.

19 Ibid., S. 292.

${ }^{20}$ Mona Ozouf, Das Pantheon. Freiheit, Gleichheit, Brüderlichkeit. Zwei französische Gedächtnisorte, Berlin 1996, S. 20.

21 Jörg Traeger, Der Tod des Marat. Revolution des Menschenbildes, München 1986, S. 126: »Das dargestellte Licht charakterisiert [...] weder die Tatzeit noch die authentische Raumsituation. [...] Gemeint ist die aufsteigende Sonne eines ungetrübten Morgens. Die diesen Schluß begründenden Merkmale stehen im Einklang mit der revolutionären Lichtsymbolik «.

${ }^{22}$ Zum Maratkult vgl. Klaus Herding, Davids "Marat« als dernier appel à l'unité révolutionnaire, in: Ders., Im Zeichen der Aufklärung, Frankfurt a. M. 1989, S. 71-94; 195-204.

$23 \mathrm{Zu}$ den einzelnen Monarchen vgl. Herding, Visuelle Zeichensystemen, S.98-100.

$24 \mathrm{Vgl}$. Donat DE Chapeaurouge, Einführung in die Geschichte der christlichen Symbole. Darmstadt ${ }^{3}$ 1991, S. 128f.; SeIdel, Kerze, S.140-142; Werner SchneiderS, Images of Light - before, during and after the Age of Enlightenment, in: Roland MORTIER, Visualisation. Concepts et symboles du dix-huitième siècle européen, Berlin 1999, S.1-9. 
Opfer Christi steht ${ }^{25}$. Die revolutionäre Umdeutung nutzt dagegen die Bedeutungsschicht des memento mori, die Reminiszenz an die Endlichkeit alles Irdischen im Lauf der Zeit. Im Gegensatz zur Sonne kann die Kerze sich nicht täglich im Sonnenaufgang selbst wieder erneuern. Die Zeit selbst kündigt nun das endgültige Ende des monarchischen Systems an: »Sous peu il n'y aura plus de tyrans, le temps trop juste vous donne la liberté et l'égalité«. Die Konstellation der Herrscher weist weit über den Titel Le Nouvel Astre français hinaus auf ganz Europa und das Osmanische Reich. Die Sonnen-Kokarde repräsentiert dabei das Verständnis des revolutionären Frankreich als »eine Feuerstätte des Lichts, ein Sonnenzentrum $\aleph^{26}$ für die Welt, worauf in der europaweiten Rezeption immer wieder direkt verwiesen wurde ${ }^{27}$. Vor allem aber verweist die Konstellation auf einen universalen Anspruch, "alle neuzeitlichen Ausprägungen der >Revolution intendieren nämlich eine Weltrevolution; zeitlich, daß sie permanent bleibt, bis ihre Ziele erreicht sind « ${ }^{28}$.

Die Verschmelzung von Sonne und Kokarde nutzt die Strukturen der zentralistischen Regierungsform des Ancien Régime. Die Sonne im Zentrum wird lediglich mit neuen Mythen aufgeladen. Ihr alles durchdringendes Licht versinnbildlicht par excellence die Vision einer universalen Revolution. Es setzt sich über den begrenzten Raum hinweg und gestaltet ihn neu

nach dem Vorbild des Raumes in der neuen Himmelsmechanik, der nach allen Richtungen für die universale Gravitationskraft durchlässig ist. Die revolutionäre Gewalt hatte die Schaffung dieser ungemeinen Öffnung des Raumes zur Folge, dieses vereinheitlichten Feldes, auf dem das aufklärende Licht (les lumières) und das Recht sich in allen Himmelsrichtungen ausbreiten konnten ${ }^{29}$.

25 Daniel Rollenhagen, Nucleus emblematium selectissimorum, Bd.1, No.31: Aliis in serviendo consumor. Dazu Böcher, Licht und Feuer, S. 115: Die Symbolik der Kerze, v. a. die seit Ende des 4. Jahrhunderts geweihte Osterkerze, stellt die Synthese kirchlicher Lichtvergleiche dar. Vgl. auch SEIDEL, Kerze, S.64f.: Die Kerze wird mit der leuchtenden Feuersäule verglichen, die dem Volk Israel nach Ex 13, 21 den Weg aus der Knechtschaft wies. In übertragener Deutung führt Christus aus der Nacht zum Licht des Glaubens, vom Tod zum Leben. Gleichzeitig steht die Kerze für den Tod Christi am Kreuz, mit dem er für die Sünden der ganzen Welt büßte: So wie er opfert sich auch die Kerze, indem sie Licht spendet und sich dabei selbst verzehrt. Der Ritus, die Taufkerze an der Osterkerze zu entzünden, verweist auf die Teilhabe am Licht des Erlösers, das mit der Lebenssymbolik des Lichtes verschmilzt.

26 Jean STARobinski, 1789. Die Embleme der Vernunft, München o. J., S. 42.

27 Ibid., S. 40f.: »Alfieri, Klopstock und Blake werden sich als Zeugen eines großen Sonnenaufgangs verstehen «. Zu Großbritannien: Ronald PAULSON, Representations of Revolution (1789-1820), New Haven u.a. 1983, S.41-47; zu Italien: Robert JoNARD, L'Italie et le mythe solaire de la Révolution française, in: Revue des études italiennes 38 (1992), S.39-53; zu Deutschland: JäGER, Politische Metaphorik, S.16-20; Ders., Metaphorik, in: Helmut Reinalter (Hg.), Lexikon zu Demokratie und Liberalismus, Frankfurt a. M. 1993, S.213-216; Helmut Koopmann, Freiheitssonne und Revolutionsgewitter. Reflexe der Französischen Revolution im literarischen Deutschland zwischen 1789 und 1840, Tübingen 1989.

28 Reinhart KosELLECK, Historische Kriterien des neuzeitlichen Revolutionsbegriffs, in: DERs., Vergangene Zukunft. Zur Semantik geschichtlicher Zeiten, Frankfurt a.M. 1989, S. 80 (Hervorhebungen von Koselleck).

${ }^{29}$ Starobinski, Embleme, S. 45. 
Die Lichtsymbolik als Zeichen der »auf ihren Anfang zurückgeführten Welt « ${ }^{30}$ des »commencement des temps « ${ }^{31}$, trägt in sich die Überhöhung eines idealisierten Naturzustandes:

Das Fortschreiten in der Geschichte wird begriffen als ein Rückschreiten auf die Natur hin. Mit der Darstellung des Despotismus als widernatürliche Herrschaft hat die bildliche Gestaltung des Zäsurbewußtseins eine neue Dimension gewonnen: der Bruch mit der politischen Ordnung des Ancien Régime bedeutet die Wiederaufnahme einer von der alten Ordnung unterbrochenen naturgesetzlich verlaufenden Geschichte; Renaturalisierung der Gesellschaft in der Überwindung des Widernatürlichen des Ancien Régime vollzieht eine durch Vernunft geleistete Versöhnung mit Natur ${ }^{32}$.

Besonders durch die am Agrarjahr orientierte Kalenderreform und die Einführung einer neuen Zeitrechnung wurde die Einheit von Natur und Neubeginn zum Ausdruck gebracht ${ }^{33}$.

Dazu kam in der »Versöhnung mit der Natur $\aleph^{34}$ auch die Befreiung von den unnatürlichen Fesseln der höfischen Gesellschaft zum Ausdruck. Die Revolution konnte sich also rühmen, der Natur ihre Würde zurückgegeben zu haben und so mit den Segnungen der Natur >belohnt $<$ zu werden. Dazu zählt auch das natürliche Licht, das als wohltuende Sonne Helligkeit und Wärme spendet, als Glorie die Revolutionshelden verklärt oder aber als strafender Blitz und zerstörendes Feuer die Feinde der Republik vernichtet.

Die Zeitenwechsel tragen dabei die wiederholte Revolution der Revolution in sich: Jeder utopische Neuanfang erklärte seinerseits das Vorhergehende zur dunklen Epoche ${ }^{35}$ und sah das eigene Verdienst in der endgültigen Ankunft des Lichts.

30 Ibid., S. 40.

31 Mona Ozouf, La fête révolutionnaire 1789-1799, Paris 1976, S.340. Dazu auch Alain Pessin, Mythe du peuple et révolution, in: Yves Chalas ( $\mathrm{Hg}$.), Mythe et révolutions, Grenoble 1990, S. 273: »Toute la ritologie révolutionnaire n'est que technique du commencement «.

${ }^{32}$ RüTtEN, Das Schauspiel Le jugement dernier des rois, S. 16. Zum philosophischen Hintergrund v. a. bei Rousseau vgl. Tilo SCHABERT, Natur und Revolution. Untersuchungen zum politischen Denken im Frankreich des 18. Jahrhunderts, München 1968, bes. S. 13-23.

${ }^{33}$ Mona Ozouf, Kalender, in: Kritisches Wörterbuch der Französischen Revolution, Bd.2, S. 754-767. Vgl. auch Reinhart KoselLECK, Anmerkungen zum Revolutionskalender und zur 'Neuen Zeit<, in: Ders., Rolf Reichardt (Hg.), Die Französische Revolution als Bruch des gesellschaftlichen Bewußtseins, München 1985, S.64: »Neu daran ist wirklich die Reflexion, die Geschichte selber beginnen zu können, indem man sich kalendarisch über sie Rechenschaft gibt «.

${ }^{34}$ Dazu ausführlich: Hans-Christian und Elke Harten, Die Versöhnung mit der Natur: Gärten, Freiheitsbäume, republikanische Wälder, heilige Berge und Tugendparks in der Französischen Revolution, Reinbek 1989.

35 Dies gilt natürlich auch für die antirevolutionäre Karikatur, wie etwa Le Dégel de la nation von 1792. Vgl. LANGLoIS, Caricature, S.222f., Abb.99 und S.172-174: Unter den Strahlen der königlichen Sonne mit den drei Lilien im Zentrum - in der Legende bezeichnet als Le soleil royal - schmilzt die Statue der Freiheit dahin, während die Revolutionäre vergeblich versuchen, den Niedergang aufzuhalten. Nach der 'Eiszeit< soll also eine wie- 


\subsubsection{Revolutionäre Apokalypse \\ Feuer und Blitz als ambivalente Naturgewalten}

Den sonnenhaften Lichtgeburten steht in der Revolutionsgraphik das Element des »strafenden Lichts $\ll^{36}$ entgegen, das meist in den Elementargewalten von Blitz, Feuer oder dem Vulkan verbildlicht wird. Der enge Zusammenhang zwischen wohltuender und richtender Funktion der Lichtsymbole zeigt sich schon in der 1790 erschienenen Darstellung La régénération de la nation françoise en $1789^{37}$. Die bereits enthüllte Wahrheit öffnet das Buch der Erkenntnis, aus dem ein heller Lichtstrahl strömt. Dieser erleuchtet die personifizierte Francia und entzündet in ihrer Hand ein Blitzebündel, mit dem sie die Feinde der französischen Nation straft, während die Völker der Erde von den Segnungen des Lichts profitieren. Der Blitz steht hier für eine neues Naturund Machtverständnis, das für die Revolution charakteristisch ist: Die Entzündung des Blitzebündels spielt direkt auf Franklins Elektrizitätslehre an ${ }^{38}$, und auf die Berechenbarkeit und Erklärbarkeit der Natur. Der Blitz wird so zum unmittelbaren Fortschrittssymbol. Traditionell war der Blitz das Attribut der Herrschergewalt des Königs, wie es im Bild des Jupiter Tonans seit der

dererstandene königliche Sonne die eigentliche Revolution vollbringen: eine Rückkehr zu den gefestigten Werten, versinnbildlicht durch das steinerne Schloß, von dessen Brüstung aus die königliche Familie beobachtet, wie das Werk der Revolutionäre in Schlamm und Schmutz versinkt. Das Schloß am rechten und die Kirche am linken Bildrand stellen die Pole dar, zwischen denen die Sonne ihre Strahlen aussendet. Der revolutionären Öffnung des (Licht-)Raumes werden so durch König und Kirche als Repräsentanten des göttlichen Lichts ihre traditionellen Grenzen aufgezeigt.

${ }^{36}$ Reichardt, Lumières, S. 132. Allg. zur Freiheit der Natur als Metapher der politischen Freiheit vgl. Martin WARNKE, Politische Landschaft. Zur Kunstgeschichte der Natur, München, Wien 1992, S. 89-134.

37 Radierung, 1790. BnF, Est. Vgl. Fischer, Wer löscht das Licht, S. 93, Abb.46. Vollständige Interpretation bei Herding, Visuelle Zeichensysteme, S. 111-113.

38 Ibid., S. 112. Benjamin Franklin, der Erfinder des Blitzableiters, war von 1776-1785 der erste amerikanische Botschafter in Frankreich. Vgl. James A. LeITH, Le culte de Franklin avant et pendant la Révolution française, in: Annales historiques de la Révolution française 226 (1976), S.543-571. Dazu auch Eberhard WeIGL, Entzauberung der Natur durch Wissenschaft - dargestellt am Beispiel der Erfindung des Blitzableiters, in: Jahrbuch der Jean-Paul-Gesellschaft 22 (1987), S. 30: »Franklin wird als neuer Prometheus, als Heilsbringer, gefeiert, der den Göttern das Feuer stahl, um es den Menschen zu bringen. Der revolutionäre Akt der Unabhängigkeit Amerikas, in der zum ersten Mal modernes Naturrecht geschichtlich wirksam wurde, wird mit der Befreiung des Menschen von dem strafenden Gott parallel gesetzt«. Diese Koppelung belegt Turgots Epigramm: „Eripuit coelo fulmen sceptrumque tyrannis« (ibid.). Politische und wissenschaftliche Errungenschaften verschmelzen hierbei in einer tiefgreifenden Infragestellung politischer und religiöser Instanzen. Zum Prometheusmythos der Aufklärung allg. vgl. Raymond Trousson, Prométhée, in: Delon, Dictionnaire, Paris 1997, S.910: »Les admirateurs du vol du feu interprètent [...] l'acte prométhéen entraînant la déchéance de Jupiter représentant l'Église et l'obscurantisme«. Zur Verbreitung der Prometheusbilder in der Revolutionsmetaphorik in Deutschland vgl. J̈̈GER, Politische Metaphorik, S. 62-65. 
augusteischen Epoche dargestellt wird ${ }^{39}$. Dabei symbolisiert Jupiters Blitz als Zepter die gottgegebene Macht der Herrscher ${ }^{40}$. In die Konstellation der Régénération ist der König zwar noch eingebunden als Beschützer der Francia (die ihn allerdings um einiges überragt) - die eigentliche Macht hält er aber nicht mehr in Händen. Die seit jeher als göttliche Aktion empfundene Entladung des Blitzes ${ }^{41}$ wurde durch die Entdeckung der Elektrizität im 18. Jahrhundert wissenschaftlich als Urkraft definiert. ${ }^{42}$ Der Blitz als "fünftes Element ${ }^{43}$ - im Verständnis der Zeit eine reinigende und somit positive $\mathrm{Na}$ turkraft ${ }^{44}$ - wurde zur »am extensivsten genutzten Revolutionsmetapher ${ }^{45}$. Der strafende Blitz war dabei stets die selbstverständliche Waffe der Revolution. Auf der Darstellung Souveraineté du peuple, déstruction du clergé et de la royauté von 1793 etwa entspringen die gegen König und Kirche gerichteten Blitze einem strahlenden Dreieck mit der Inschrift $\mathrm{LOI}^{46}$. Hervorgerufen wird das , Gewitter ` durch den mit einer phrygischen Mütze gekrönten Speer eines auf dem Dreieck thronenden Sansculotten. Der Vergleich der Revolutionäre mit den Naturgewalten warf gleichzeitig die Frage nach der Beherrschbarkeit der Ereignisse auf ${ }^{47}$. Unter der Terreur entstand aus der Metaphorik der Naturkatastrophen die Angst vor einer nicht mehr steuerbaren Revolution und daraus »ein Gefühl der Zukunftsohnmacht « ${ }^{48}$. In der Bildpublizistik

39 Zur Entwicklung des Jupiter Tonans als Sinnbild der göttlich rechtfertigten Herrschaft vgl. Manfred Beller, Jupiter Tonans. Studien zur Darstellung der Macht in der Poesie, Heidelberg 1979.

${ }^{40}$ Ibid., S.92. Vgl. die Darstellung auf der Trajanssäule in Rom: Jupiter übergibt Trajan das Blitzebündel. Zur Verherrlichung Ludwigs XI. als Jupiter Tonans ibid., S. 102f. Zur analogen Darstellung in der Bildpublizistik vgl. Wolfgang Cillessen (Hg.), Krieg der Bilder. Druckgraphik als Medium politischer Auseinandersetzung im Europa des Absolutismus, Berlin 1997, S. 223, Abb. C.II.5.

41 Zur Mythologie des Blitzes vgl. Chapeaurouge, Einführung, S.118f.

42 Ernst BENZ, Theologie und Elektrizität. Zur Begegnung und Auseinandersetzung von Theologie und Naturwissenschaft im 17. und 18. Jahrhundert, Wiesbaden 1971, S.7. Der Blitz als sichtbare Entladung von Energie, als »überwältigendes, blendendes Licht, als zerstörerische Gewalt in ihrer numinosen, irrationalen Form« (ibid.), wurde so ein neues Symbol Gottes. Daraus entwickelte sich Mitte des 18. Jahrhunderts eine Naturphilosophie, wonach die ursprünglichste Manifestation Gottes, das Licht des ersten Schöpfungstages, das elektrische Feuer der Natur gewesen sei (ibid., S. 46-48).

43 Olaf Briese, Die Macht der Metaphern. Blitz, Erdbeben und Kometen im Gefüge der Aufklärung, Stuttgart, Weimar 1998, S.42. Zur Blitzmetaphorik: Ders., Aufruhr der Elemente. Politische Metaphorik bei den Romantikern, in: Literaturwissenschaftliches Jahrbuch N.F. 40 (1999), S. 155-175.

44 Briese, Macht der Metaphern, S. 44-66.

45 JäGER, Metaphorik, S.214.

46 Radierung, Herbst 1793. BnF, Est. Vgl. Herding, Reichardt, Bildpublizistik, S.147, Abb. 194. Noch auf einer Zeitungsillustration von 1790 mit dem Titel La Liberté triomphe et détruit les abus schleudert die allegorische Liberté das Blitzebündel auf Wappen, Kronen und andere Repräsentanten der Macht. Ibid., S.149, Abb. 198.

47 Joachim von der ThüseN, „Die Lava der Revolution fließt majestätisch «. Vulkanische Metaphorik zur Zeit der Französischen Revolution, in: Francia 23/2 (1995), S. 116f.

48 Ibid., S. 116. 
bleibt demgegenüber das Deutungsmuster der Revolution als naturgesetzmäBige Umwälzung bestimmend, die entfesselte Natur richtet sich nur gegen ihre Feinde. Die stürmische Natur ist nicht nur der angemessene Hintergrund für den historischen Wendepunkt, sondern läßt auch apokalyptische Konnotationen wie Vulkanausbrüche in den Vordergrund treten. Das Feuer nimmt dabei als Symbol von Zerstörung und reinigender Erneuerung gleichermaßen einen zentralen Platz ein ${ }^{49}$. Es verkörpert die revolutionäre Aktion per se: "Das Lichtsymbol der Aufklärung entbrennt zum Feuerbild ihrer politischen Verwirklichung: der Revolution ${ }^{50}$.

Die als Verbrennung dargestellte Überwindung des Ancien Régime wurde dabei zum Leitmotiv und immer wieder thematisiert, so auch in einer Radierung, die der im Juni 1792 beschlossenen Aufhebung des Adels gewidmet war ${ }^{51}$.

Die Vorstellung des feurigen Strafgerichts als säkularisierte Apokalypse war besonders während der Terreur sehr verbreitet. Schon das Inkrafttreten der Verfassung von 1793 wurde als mit von Blitz und Feuersturm begleiteten Lichtexplosionen dargestell ${ }^{52}$, wobei das direkt mit der radikalen Montagne verbundene Symbol des heiligen Berges ${ }^{53}$ vulkanische Züge annahm ${ }^{54}$. Der Vulkan, schon vor der Französischen Revolution ein Symbol für die Freisetzung von Energie und für politischen Veränderungswillen ${ }^{55}$, wurde nun zur

49 Herding, Reichardt, Bildpublizistik, S.50f., Thüsen, Lava, S.122f.; Demandt, Metaphern für Geschichte, S.138f.

${ }_{50}$ Hans-Wolf JÄGER, Politische Kategorien in Poetik und Rhetorik der zweiten Hälfte des 18. Jahrhunderts, Stuttgart 1970, S. 49.

51 Kolorierte Radierung, 1792 (?). BnF, Est. Coll. de Vinck 3615. Vgl. Herding, Reichardt, Bildpublizistik, S. 50, Abb. 59.

52 Reichard, Lumières, S. 138, Abb. 30: La Constitution républicaine, semblable aux tables de Moyse, sort du sein de la Montagne au milieu de la foudre et des éclairs. Die in Ex 19, 16-19 beschriebene vulkanische Mutation des Sinai als Zeichen der Theophanie wird auf den überirdischen Charakter der Naturrechte übertragen.

53 Zur Symbolik der Montagne vgl. Thüsen, Lava, S.121-128 und Monique Mosser, Le temple et la montagne: généalogie d'un décor de fête révolutionnaire, in: Revue de l'art 83 (1989), S. 21-33. Zur Symbolik des Berges als Tugend- und Erhabenheitssymbol Ende des 18. Jahrhunderts vgl. Simon Schama, Der Traum von der Wildnis. Natur als Imagination. München 1996, S. 497-526.

$54 \mathrm{Zu}$ Belegen aus Reden im Nationalkonvent vgl. ThÜsEN, Lava, S.127.

55 Dazu am Beispiel des sog. Steins in Wörlitz: Maiken UMBach, Visual Culture, Scientific Images and German Small-State Politics in the Late Enlightenment, in: Past and Present 158 (1998), S. 130: «Rather, volcanism was a way of picturing political development as an unfolding of dormant energies, as an >Awakening shich manifested itself in a series of sudden dramatic changes . Zum Zusammenhang zwischen zeitgenössischen Vulkanismustheorien und Französischer Revolution vgl. Bernhard Fritscher, Vulkanismusstreit und Französische Revolution. Gedanken zu einer zeitlichen Parallele, in: Géosciences / Geowissenschaften. Bochum 1991, S.169-185; Ders., Die Entmoralisierung der Naturgewalten. Vulkane und politische Revolution im System der Natur, in: Jahrbuch der österreichischen Gesellschaft zur Erforschung des 18. Jahrhunderts 14/15 (2000), S. 217-237. Allg. zu den Zusammenhängen zwischen Vulkanismus und Apokalypse vgl. Hans Ulrich RECK, 
unmittelbaren naturrechtlichen Legitimation revolutionärer Gewalt ${ }^{56}$. Durch die Ausweitung auf den endzeitlichen Kampf zwischen Licht und Finsternis trat auch das Motiv des mit dem Begriff der Revolution eng verknüpften Weltenbrandes in den Vordergrund ${ }^{57}$ und führte zu millenaristischen Interpretationen der revolutionären Ereignisse ${ }^{58}$ : $\gg$ Die Apokalypsedeutung wird [...] ausdrücklich historisiert. Die Französische Revolution bringt die Erlösung, die von den biblischen Texten und der mystischen Tradition angekündigt wurde $\ll^{59}$.

Auf dem am Tage von Robespierres Sturz, dem 27. Juli 1794 (9 Thermidor II) veröffentlichten Blatt Le Triomphe de la République ${ }^{60}$ erstrahlen die Gesetzestafeln auf dem Gipfel des Feuer und Blitze spuckenden Vulkans in hellem Lichtschein, während das befreite Volk am Fuße des Berges erlöst um einen Freiheitsbaum tanzt.

Die Instrumentalisierung des Bedrohlichen in der Natur trägt so auch zur Überwindung der Angst bei: Die Revolution, die sich mit der Natur ausgesöhnt glaubt, kann die ambivalente Naturmetaphorik durch ein »Versprechen der Sinnfülle $\ll^{61}$ rechtfertigen.

\subsubsection{Die Lichtsymbolik der Französischen Revolution als »transfert de sacralité"}

Die kaum zu überschätzende Bedeutung der Lichtsymbolik in der Französischen Revolution kann mit dem Begriff der »Säkularisierung« nicht ausreichend erklärt werden.

Vulkanismus und Apokalypse. Zum Motiv des Feuers und einigen Derivaten von >Nature in Weltkonstruktionen und Kunstkonzepten der Moderne im Hinblick auf die sgranulare Synthese،, bes. S. 186f., S. 190-193.

56 Thüsen, Lava, S.131. Zu Erdbeben und Vulkan in der Revolutionsmetaphorik vgl. BrIESE, Macht der Metaphern, S. 162-178. Das berühmteste Beispiel der Feuerbergmetaphorik stellt wohl Sylvain Maréchals 1793 uraufgeführtes Theaterstuick Le Jugement dernier des rois dar, in welchem die Könige Europas von einem Vulkan verschlungen werden. Dazu Thüsen, Lava, S.129-132; Rürten, Das Schauspiel Le Jugement dernier des rois, S.5-8. Das 1833 entstandene Blatt Troisieme Eruption du volcan de 1789 zeigt die Ereignisse des Juli als europaweiten Ausbruch der als helle Feuerwolke dargestellten Liberté. (Vgl. Herding, Reichardt, Bildpublizistik, S.153, Abb. 206.)

57 Dazu Melvin Lasky, Utopie und Revolution, Reinbek 1989, S.491-499.

${ }^{58}$ Dazu Jochen SchloBaCh, Fortschritt oder Erlösung? Zu aufklärerischen und millenaristischen Begründungen der Revolution, in: Annalen der internationalen Gesellschaft für dialektische Philosophie 6 (1989), S. 27-40.

59 Ibid., S. 31 (Hervorhebung von Schlobach).

60 Übermalter Stich, datiert 27.7. 1794. BnF, Est., Coll. de Vinck 5012. Vgl. Oberlé, Rue. S. 105, E 253. Der Bildtext lautet: »Les Despotes cruels dont nous bravons la rage, / Euxmêmes sur leur tête ont provoqué l'orage / De la Montagne enfin ils sont précipités / Ces monstres furieux par le crime enfanté / Et les traits foudroyants qu'ils lançaient sur leur proie / Sont pour nous aujourd'hui le plus beau feu de joie«.

61 Thüsen, Lava, S. 115. 
Bildliche Formen, die traditionell der Veranschaulichung von Glaubensbotschaften und allegorischer Herrscherverehrung vorbehalten waren, wurden mit den Ideen der Aufklärung und Revolution neu besetzt, wodurch ein tiefgreifender Substitutionsprozeß in Gang gesetzt wurde. Dabei durchliefen die Strukturen der "barocken Verherrlichungsmuster ${ }^{62}$ in Verbindung mit der revolutionären Lichtsymbolik eine Entwicklung, die den erweiterten Erfahrungshorizont des kosmologischen und des sich infolgedessen verändernden politischen Bewußtseins spiegeln: Durch den Siegeszug der experimentellen Naturwissenschaften erhielt »Licht « den Rang eines entschlüsselbaren Natursymbols und wurde so zur unendlich erweiterbaren Projektionsfläche für den menschlichen Fortschritt:

In dem Maße, in dem Analyse und Reflexion dem Licht die überirdische Verkündigungsaura nahmen, dem die christliche Religion nicht nur ihre spirituelle Autorität verdankte, bekam die empirische Wirklichkeit mehr Gewicht, wurde das physikalische Phänomen >Licht zur Voraussetzung und zum Inbegriff der sachlichen Erhellung der Naturprozesse. [...] Kein Licht-Messias war nun gefragt, sondern ein experimentierender Verstand, der den Naturgewalten ihre Bedrohung zu nehmen und sie zu bändigen wei $\beta^{63}$.

Das natürliche Licht richtet sich an den Verstand, das lumen naturale, das nach Descartes als aktiv zu nutzende faculté zu verstehen ist und nicht mehr als göttliche Gnade. "Licht « konnte in der Bildsprache von Aufklärung und Revolution somit ganz als Symbol der neuen Ordnung besetzt werden. Die didaktische Absicht der bildlichen Darstellungen lehnt sich dabei eng an die Tradition des göttlich gelenkten Lichtstrahls an. Das umgeleitete, gebrochene, durch Spiegel und Brenngläser intensivierte Licht symbolisiert die Wege der Erkenntnis und die daraus erwachsende Macht. Diese Lichtdynamik hängt eng mit der Rolle der Lichtbewegung in Newtons Gravitationslehre zusammen $^{64}$ : Die unaufhörliche Bewegung von Planeten und Licht im Raum stellt einen Gegensatz zu Descartes statischem Ätherkosmos dar und hebt diesen auf. Die Mobilität des Universums stellt, auf die politische Metaphorik

62 Werner HofmanN, Wahnsinn und Vernunft. Über die allgemeine Sonne und das Lampenlicht des Privaten, in: Ders. (Hg.), Europa 1789: Aufklärung, Verklärung, Verfall, Ausstellungskatalog, Hamburg, S. 28.

63 Ibid., S. 25. Besonders Isaac Newton wurde in ganz Europa zum Abgott verklärt. Seine Forschungen zur Lichtbrechung, die als Entschlüsselung der Natur des Lichts gefeiert wurden, ließen ihn als Lichtbringer und Lichtschöpfer gleichermaßen erscheinen, wie es besonders in dem berühmten Epigramm von Alexander Pope zum Ausdruck kommt: „Nature and Nature's law lay hid in night: God said, Let Newton be - and All was Light«. Zum Newtonkult vgl. Fritz WAGNER, Zur Apotheose Newtons. Künstlerische Utopie und naturwissenschaftliches Weltbild im 18. Jahrhundert, München 1974; Francis HaSKELL, Die Apotheose Newtons in der Kunst, in: Ders., Wandel der Kunst in Stil und Geschmack: Ausgewählte Schriften, Köln 1990, S.13-38.

64 Eine bezeichnende Rolle spielten dabei auch die Freimaurer, denen u. a. auch Franklin angehörte. Vgl. Margaret C. JACOB, The Radical Enlightenment. Pantheists, Freemasons and Republicans, London 1981, S.106: »Freemasonry was one of the most extraordinary phenomena of that rationalist age, and its rise is directly linked to the triumph of a new scientific culture to the Newtonian version of enlightenment«. 
übertragen, die Unveränderlichkeit der Verhältnisse radikal in Frage ${ }^{65}$. Die Konsequenz ist die letztendliche Identifikation von astronomischem und politischem Revolutionsbegriff ${ }^{66}$. Die traditionelle Zeitsymbolik der Sonne wird durch die Lichtdynamik gleichfalls modifiziert, so daß aus dem Mythos der ewigen Wiederkehr der moderne Fortschrittsgedanke entsteht ${ }^{67}$. Mit der Übernahme apokalyptischer Vorstellungen wird zudem die Schaffung eines neuen Welt- und Zeitmodells evoziert, das den natürlichen Verfall ausschließt. Der Vorbildcharakter kosmischer Gesetze für politische Veränderungen erklärt die Gültigkeit traditioneller Raumstrukturen für die Bildsprache der Revolution. In den allegorischen Darstellungen bleibt das Verhältnis von oben und unten unberührt: Sonne und Lichtstrahlen, Blitz und Feuer spukkende Berge, die Opposition des Lichten, Hehren und Erhabenen gegen das Niedrige, Finstere und Unwissende rechtfertigen die Aufrechterhaltung des hierarchisch-vertikalen Weltbildes, während das horizontal-egalitäre Modell eine untergeordnete Stellung einnimmt. Mit dieser Vertikalität korrespondiert die Bedeutung der Natur als höchster Instanz, was auch die unkontrollierbaren Seiten der Natur integriert. War bereits für die von Newton stark beeinflußten Physikotheologen ${ }^{68}$ die Natur in ihrer Gesamtheit - auch mit ihren vorher als feindlich empfundenen Erscheinungen - ein Gottesbeweis, zeugt sie im revolutionären Empfinden von der Gesetzmäßigkeit des gesellschaftlichen Wandels und politischen Umsturzes. Die Möglichkeit, Kräfte wie die Elektrizität zu bändigen, trug davon unberührt zum optimistischen Fortschrittsdenken bei.

Die enge Verbindung zwischen dem Kult der Natur und dem des Etre suprême führt zu einer naturmystischen Aufladung der Lichtsymbolik: Die im

${ }^{65}$ Simmen, Vertigo, S. 39. Vgl. auch Grenet, Passion, S. 265: „Détruire l'ancien cosmos, c'est changer la conception de l'homme«.

${ }^{66}$ Dazu Griewank, Revolutionsbegriff.

67 Wichtig für die parallele Aufladung des Sonnenmotivs mit der Metaphorik des Lichtzentrums und der unablässigen Bewegung war das im späten 17. Jahrhundert bevorzugte Weltbild von Tycho Brahe. Im Tychonischen Kosmos drehen sich die Planeten um die Sonne, diese mit den Planeten sich aber um die Erde. Dazu Wolfschmidr, Nikolaus Kopernikus, S. 48. Vor allem Ludwig XIV. machte sich diese doppelte Motivation für die Aufladung seiner Sonnensymbolik zunutze: Die herausragende Stellung der Sonne erklärt sich "par la lumière qu'il communique aux autres astres qui lui composent comme une espèce de cour « und gleichzeitig durch "son mouvement sans relâche «, sowie "cette course constante et invariable«. Vgl. Louis XIV, Mémoires, année 1662, S.136. Diese Untrennbarkeit von Sonnen-, Bewegungs- und Fortschrittsmetaphorik zeigt sich noch in Traviès' Karikatur Il serait plus facile d'arrêter le soleil in: La Caricature, 20.12.1833 mit der strahlenumglänzten Freiheit auf einem Triumphwagen, den ihre Gegner erfolglos aufzuhalten versuchen.

${ }^{68}$ Das zentrale Thema der im England des 17. Jahrhunderts entstandenen Physikotheologie war die Integration neuer wissenschaftlicher Erkenntnisse in das christliche Weltbild. Zur Lichtsymbolik der Physikotheologen und zur Bezugnahme auf den göttlichen Glanz, den kabod-doxa-Kompex, vgl. bes. Wolfgang PhilipP, Das Werden der Aufklärung in theologiegeschichtlicher Sicht, Göttingen 1957, S. 100 f. 
Freien abgehaltenen Feste ${ }^{69}$ zeugen von einer rituellen Verehrung des Höchsten Wesens durch das natürliche Licht. Das in der christlichen Architektur seit dem Mittelalter zunehmend betonte Element des religiösen Lichterlebnisses und die stetig wachsende Bedeutung des natürlichen Lichts werden während der Französischen Revolution zur allein gültigen Manifestation des göttlichen Elements ${ }^{70}$.

Die Besetzung der solaren Herrschersymbolik greift auch die eng damit verbundenen Ansprüche der Hegemonie und Weltherrschaft auf, gerechtfertigt nun nicht mehr durch das Gottesgnadentum, sondern durch das Naturrecht. Gleichzeitig werden durch die Erwartung einer diesseitigen Heilserfüllung auf gesellschaftlicher und politischer Basis Elemente der christlichen Endzeiterwartung in die Geschichte integriert und ihre Erfüllung propagiert ${ }^{71}$. Die Symbolik des natürlichen Lichts (lumen) vereint sich so mit dem transzendenten Licht (lux), das nun aber als dem menschlichen Verstand unmittelbar zugängliche Größe zum Symbol für selbständige Erkenntnis wird. Darin besteht der eigentliche transfert de sacralité ${ }^{72}$.

\footnotetext{
69 Mosser, Temple.

70 Dies zeigen auch Pläne für Tempelkulte des Höchsten Wesens: »Im Inneren wirft das Auge des Höchsten Wesens sein Licht (!) auf die Tafeln der Menschenrechte und der Verfassung. [...] Während der Zeremonie soll der Mensch aufrecht stehen, den Blick zum Höchsten Wesen und zum Licht des Himmels gerichtet«. Nesrolat, Plan d'un culte à l'Être suprême, Prairial II, zitiert nach: HarTen, Versöhnung, S. 109. Zur Veranschaulichung des Etre suprême durch die Augensonne vgl. ReICHARDT, Lumières, S.140. Allgemein kommt im Augensymbol, das häufig den Platz der hoch am Himmel stehenden Sonne einnimmt, der Anspruch auf Allgegenwart zum Ausdruck, und damit die kompromißlose Durchdringung der Gesellschaft mit den Idealen der Revolution. Grundlegend dazu: Waldemar Deonna, Le symbolisme de l'œil, Paris 1965. Zum Auge in der Französischen Revolution vgl. Herding, ReICHaRdt, Bildpublizistik, S. 44-49.

71 In der politischen Bildpresse des 17. Jahrhunderts symbolisierten Lichtmanifestationen noch die göttliche Gnade, die über einer Herrscherpersönlichkeit oder einer Gruppierung wachte oder durch sie waltete. Dazu vielfältige Beispiele bei Cillessen, Krieg der Bilder. $72 \mathrm{Zu}$ diesem Begriff Ozouf, Fête, bes. S. 329-340.
} 


\subsection{Die Entwicklung der Licht-Finsternis-Symbolik seit der Restauration}

\subsubsection{Der Löschhütchenkrieg 1815-1830: Lichtfeinde versus Aufklärer}

Das postrevolutionäre Schicksal der lumières bildete seit 1815 den thematischen Schwerpunkt der Bildpublizistik. Nach der Vereinnahmung revolutionärer Lichtmythen und traditioneller Herrscherallegorien durch Napoleon ${ }^{73}$ führte die Gleichsetzung der Restauration mit Reaktion und Unterdrückung der Aufklärung zu einer regelrechten Symbolschlacht, einem Kampf zwischen Licht und Finsternis ${ }^{74}$. Die reaktionären >Finsterlinge< wurden dabei als aggressive Angreifer dargestellt, die das Licht der Aufklärung - Grundlage für Fortschritt und Freiheit - auslöschen wollen. Als Waffe diente dabei das Löschhütchen (éteignoir), das sich schnell zum Symbol schlechthin für die Vertreter der alten Ordnung entwickelte ${ }^{75}$.

Noch während der Ersten Restauration, am 25. Dezember 1814, verkündete die napoleonnahe Zeitschrift Le Nain jaune die Gründung des ordre des chevaliers de l'Éteignoir, womit auf die 1810 gegründeten, ultrakonservativen chevaliers de la Foi angespielt wurde. In einer satirischen Umkehrung der aufklärerischen Lichtmetaphorik formulieren die Ordensstatuten ihre Ziele, nämlich l'extinction des lumières und la guerre contre les lumineux ${ }^{76}$. Eine Karikatur im Nain jaune von 15. Februar 1815 zeigt die Aufnahme eines neuen Mitgliedes als rituelle Lichtauslöschung in einem Ambiente, das ganz im Zeichen des Rückschritts und der Finsternis steht ${ }^{77}$. Davon zeugt nicht nur die Allgegenwart des Löschhütchens, sondern auch die mittelalterliche Kathedra-

73 ReIchardT, Lumières, S. 142-145.

74 Zur analogen Polarisierung der Sprache Ende des 18. Jahrhunderts in Deutschland vgl. Horst Stuke, Aufklärung, in: Geschichtliche Grundbegriffe, Bd. 1 (1972), S. 280.

75 Zur Ikonographie des Löschhütchens vgl. allg. FISCHER, Wer löscht das Licht, sowie Klaus SchrenK, Die republikanisch-demokratischen Tendenzen in der französischen Druckgraphik 1830-1852, Marburg a.d. Lahn 1976, S.224-230. Speziell zur Restauration vgl. ReICHARDT, Lumières, S. 145-148. Das Löschhütchen erschien bereits in der Graphik der Revolutionszeit, wo es sich gegen das Ancien Régime direkt richtete: Auf der Darstellung Les Ténèbres constitutionnelles (REICHARDT, Lumières, S. 122) von 1792 symbolisiert die dem Karfreitagsritus nachempfundene Auslöschung der Lichter den Verlust der Privilegien. Auch Chronos in Le Nouvel Astre français beendet die Ära der Könige mit einem Löschhütchen, vgl. dazu Kap.3.1.1. In der 1792 entstandenen Graphik Combat des nesfles et marrons dindes [sic] du temple ou Fureur aristocrate contre le député Marat wird der Temple als Gefängnis der königlichen Familie selbst zum Löschhut: Einer der Turmkegel trägt die Aufschrift Éteignoir de royauté. Abgebildet bei Michel VovelLe, La Révolution française. Image et récit, Paris 1986, III, S. 74

76 Reichardt, Lumières, S. 148f;; Fischer, Wer löscht das Licht, S. 55f. Dort auch der vollständige Wortlaut der statuts organiques.

77 Lemaire, Réception d'un chevalier de l'Éteignoir. Kolorierte Radierung, 14.2. 1815. BnF, Est., Coll. de Vinck 10288. Reichardr, Lumières, S. 150, Abb. 38. 
le und die Sonnenfinsternis, die durch ein Fenster zu sehen ist ${ }^{78}$. Durch die offensichtliche Umkehrung freimaurerischer Erleuchtungsriten wird die Unterdrückung der lumières angeprangert ${ }^{79}$.

Der Streit um das Licht verlagerte sich während der 100 Tage zunächst auf die Opponenten Ludwig XVIII. und Napoleon ${ }^{80}$. Während der Zweiten Restauration dagegen wurde der Bilderkrieg zwischen idealisierten Aufklärern auf der einen und Klerikern oder Ultraroyalisten als Lichtfeinde auf der anderen Seite ausgetragen. Die Verteidiger des Lichts gerieten dabei anfangs in die Defensive. Das bedrohte Licht erscheint folgerichtig vorwiegend in Verbindung mit der leicht zu löschenden Kerze, die gleichzeitig das kultivierte, gezähmte Licht repräsentiert ${ }^{81}$. Die Propagierung der Aufklärung als gefährdetes Kulturgut distanzierte sich so bewußt von der aggressiven Feuer- und Naturkatastrophenmetaphorik der Revolutionszeit. Deshalb erscheint auch die Fackel, die besonders unter dem Direktorium das Sinnbild des machtvollen Lichts der Vernunft gewesen war, das der Genius der französischen Republik über ganz Europa verbreitete ${ }^{82}$, nunmehr in der Hand der Lichtfeinde: Ein 1817 publiziertes Flugblatt zeigt Rousseau und Voltaire im hellen Lichtkranz eines mit Kerzen besetzten Leuchters, den der blinde Fanatismus löschen will, während er selbst mit seiner Brandfackel nur schwarzen Rauch verbreitet ${ }^{83}$. Das Feuer

78 Réception d'un chevalier de l'éteignoir. Ausführliche Interpretation bei FISCHER, Wer löscht das Licht, S.57f.; ReICHardt, Lumières, S.149f. Die Abwertung der Gotik steht noch ganz in der Tradition des gotischen Barbaren, der die Kultur zerstört. Auch Emanuel SiÈyes, Qu'est-ce que le Tiers État?, beschrieb den Feudalismus unmittelbar vor der Französischen Revolution mit dieser Metapher: »Dans la longue nuit de la barbarie féodale, les vrais rapports des hommes ont pu être détruits, toutes les notions bouleversées, toute justice corrompue; mais au lever de la lumière, il faut que les absurdités gothiques s'enfuient, que les restes de l'antique férocité tombent et s'anéantissent«. Vgl. Édition critique avec une introduction et des notes par Roberto Zapperi, Genf 1970, § III.

79 Reichardt, Lumières, S.150. Auch die >Mitgliedsurkunden< des Löschhut-Ordens spielen auf die Freimaurerdiplome an. Ibid., S.151, Abb.39.

80 Auf der im Juni 1815 entstandenen Radierung Le Crépuscule etwa kommt Napoleon unter einem großen Löschhut hervor und bringt so den darauf sitzenden König zu Fall. Dazu Annie Duprat, L'éteignoir, in: Ridiculosa 8 (2001), S. 124f. Dagegen klagt ein wenig später entstandenes Blatt Napoleon als wahren Großmeister des Löschhütchen-Ordens an und verweist so auf die Metaphorik des Nain jaune zurück. Vgl. Fischer, Wer löscht das Licht, S. 73, Abb. 31: Napoléon véritable grand maître de l'ordre de l'Éteignoir.

811929 formulierte Gaston Bachelard, La flamme d'une chandelle, Paris ${ }^{7} 1984$, S. 25 , diese neuzeitliche geistesgeschichtliche Metaphorik der Kerze: „Cette lumière, un souffle l'anéantit, une étincelle la rallume«. Die Kerze als Medium, das auch den kleinsten Funken zu einem Licht werden läßt, löst die in der barocken Emblematik verbreitete Deutung der Kerze ab, die Licht schenkt und sich dabei verzehrt. (Vgl. dazu Kap.3.1.1.)

82 Dazu August Boppe, Raoul Bonnet, Les vignettes emblématiques sous la Révolution, Leipzig 21975, S.91, Abb. 136, sowie S.92, Abb.138. Zur wachsenden Bedeutung der Fakkel als Symbol während der französischen Revolution vgl. ScHNeIDERS, Images, S. 4.

${ }^{83}$ Radierung, 18.4.1817. BnF, Est., Coll. Histoire de France M. 108902. Unsigniert: Minerve protégeant Jean-Jacques et Voltaire contre le fanatisme, vgl. ReIchaRd, Lumières, S. 148, Abb. 37. Dazu Fischer, Wer löscht das Licht, S. 18-20 allerdings mit falscher Datierung 1794, REICHARDT, Lumières, S. $145 \mathrm{f}$. 
entbrennt zum Scheiterhaufen, der die Werke der Aufklärung verzehrt. Diese Pervertierung der Lichtmetaphorik bringt der Refrain von Bérangers Lied Les Diables missionnaires zum Ausdruck: »Vite, soufflons, soufflons, morbleu!/ Éteignons les lumières / Et rallumons le feu $\ll^{84}$.

So lautet auch der Titel einer 1819 in der liberalen Zeitung La Minerve erschienenen Karikatur, die das geistige Zerstörungswerk des reaktionären Klerus anprangert ${ }^{85}$. Eine Gruppe von Jesuiten ist dabei, die Lichter der großen Geister des 18. Jahrhunderts auszulöschen - von Voltaire über d'Alembert bis Franklin. Währenddessen schüren zwei andere Geistliche das durch eine Brandfackel entfachte Feuer, dem die Werke der Verfemten übergeben werden: neben philosophischen und staatstheoretischen auch naturwissenschaftliche Bücher ${ }^{86}$. Der unter der Restauration wiedererlangte Einfluß der Kirche auf Erziehung und Schulwesen ${ }^{87}$ bildet den Hintergrund dieser Schreckensvision, die ein neues finsteres Mittelalter ankündigt. Gleichzeitig wird der Extremismus jeglicher Couleur verurteilt: Mit dem Feuer, einst das Gewaltsymbol der Montagne, setzt die Reaktion ihrerseits das zerstörerische Werk der Terreur fort: Unter den >ausgelöschten $<$ Vertretern des 18. Jahrhunderts befinden sich auch Condorcet und Lavoisier, die schon Opfer der Schreckensherrschaft wurden ${ }^{88}$ und deren geistiges Erbe nun erneut in Gefahr ist. Auch das königliche Versprechen einer charte constitutionnelle wird verbrannt - doch gerade die Charte wird für die Liberalen zum Meilenstein ihres letztendlichen Triumphs, wie die Karikatur Grand combat entre les libéraux et les ultras (1819) beweist ${ }^{89}$. Kaum ein anderes Blatt thematisiert die Symbolschlacht dieser Epoche anschaulicher: Die Ultraroyalisten, zu erkennen an Details des Ancien Régime wie Culottes und Zöpfen, bombardieren die auf der sicheren Festung der Charte stehenden Liberalen mit roten Mützen, die an diesen jedoch abprallen. Dagegen nehmen die von den Liberalen zielsicher geworfenen Löschhüte den Ultras nach und nach die Sicht ${ }^{90}$.

84 Erschienen in La Minerve No.63, 1819. Dazu Reichardt, Lumières, S. 153, Anm. 132.

85 Kolorierte Radierung in der Zeitung La Minerve, April 1819. BnF, Est., Coll. de Vinck 10302, vgl. Reichardt, Lumières, S.54, Abb.41. Gesamtinterpretion bei Fischer, Wer löscht das Licht, S.86-92, ReIchardT, Lumières, S. 153-155. Noch 1830 griff Grandville dasselbe Motiv auf. Bei ihm sind die Blasebälge und Löschhütchen an die Stelle der Köpfe getreten. Vgl. Fischer, Wer löscht das Licht, S. 126.

${ }^{86} \mathrm{Zu}$ den einzelnen Philosophen und Wissenschaftlern vgl. Fischer, Wer löscht das Licht, S. 88-92.

87 Ibid., S. 88.

88 Jean Tulard, Frankreich im Zeitalter der Revolutionen 1789-1851, Stuttgart 1989, S. 179.

${ }^{89}$ Unsigniert, Grand combat entre les libéraux et les ultras. Kolorierte Radierung. 1819, BnF, Est.

90 Dazu Fischer, Wer löscht das Licht, S. 81-84, mit unhaltbarer Deutung: Fischer nimmt fälschlicherweise an, daß die Werfer der roten Mützen die Liberalen darstellen, während die Ultras sich zu den Beschützern der Charte stilisieren. Er übersieht dabei die Häufung von für das Ancien Régime typischen Symbolen bei den Mützenwerfern und glaubt statt dessen, daß die modische Kleidung der liberalen Löschhütchenwerfer diese als $»$ Restaurationsritter identifiziert. 
Die rote Mütze wird zur - wenig wirksamen - Waffe der Ultrarechten, die sie den Liberalen zwangsweise aufsetzen will. Einer der Mützenwerfer sagt: »En dépit de Minerve nous vous appellerons bonnets rouges «. Am Schutzschild der Liberalen prallt die Beschimpfung als "rote Mütze« freilich ab. Als Verteidiger der Charte und damit der konstitutionellen Monarchie leiten die Liberalen sich von der Gironde her und identifizieren sich keineswegs mit der radikal revolutionären Gesinnung, die durch die rote Mütze zum Ausdruck kommt, sondern distanzieren sich von revolutionären Umtrieben sowohl von 1793 wie auch von $1815^{91}$. Der Versuch, die Liberalen zu Radikalen zu erklären, scheitert somit, wohingegen die Löschhütchen ihr Ziel sehr wohl erreichen, denn sie spassen< den Ultrarechten schlichtweg perfekt. Das Löschhütchen wird den radikalen Ultras zum Verhängnis: Sie selbst werden nun ausgelöscht.

Ähnlich wird auch der Sturz der bourbonischen Dynastie in der Julirevolution von 1830 dargestellt. Die gegen die Charte und die konstitutionelle Monarchie gerichtete Politik

Karls X. sowie die Rückgabe alter Privilegien an den Klerus ${ }^{92}$ machten den König in der Bildpresse zum Löschhut per $\mathrm{se}^{93}$. Mit ihm sollte stellvertretend auch die Reaktion endgültig erstickt werden ${ }^{94}$. Der Sieg sollte sich jedoch auch diesmal als trügerisch erweisen.

\subsubsection{Die Licht- und Finsternissymbolik in der Bildpresse}

von der Julimonarchie bis zum Ende des II. Empire (1830-1870)

Den Übergang von der Restauration zur Julimonarchie kennzeichnete eine wichtige Entwicklungsstufe der politischen Karikatur: Zu Einblattdrucken und Zeitungsbeilagen trat nun das illustrierte satirische Magazin. Auf die von 1829 bis 1830 erscheinende La Silhouette folgte Charles Philipons legendäre Zeitschrift $L a$ Caricature, die aufgrund der rigiden Pressegesetze von $1835 \mathrm{ihr}$ Erscheinen einstellen mußte und von dem täglich erscheinenden Le Charivari

91 Die Antwort der Liberalen lautet wörtlich: »Nous n'aimons pas plus celui [d.i. le bonnet rouge] de 1793 que celui de 1815 «. Zur Polarisierung der Politik zwischen Liberalen und Ultras vgl. Tulard, Frankreich, S.315f.

92 Ibid., S. 333-338.

93 Reichardr, Lumières, S.158, Abb.43: Nouveau modèle de l'éteignoir: Der Kopf Karls $\mathrm{X}$. auf einem Löschhut. Kolorierte Lithographie vom 9.9.1830.

94 Karikaturen von 1830 zeigen etwa, wie ein revolutionärer Arbeiter und ein Nationalgardist gemeinsam dem König den Löschhut überstülpen. Vgl. Reichardr, Lumières, Abb.44: Coiffure à la Rambouillet inventée et exécutée par la population parisienne. Auf dem Blatt $A$ c'te niche! treibt einer der Kämpfer von der Straße die bezopften Repräsentanten des Regimes mit der Peitsche in einen großen Löschhut. Vgl. Fischer, Wer löscht das Licht, S. 104, Abb. 56. 
abgelöst wurde ${ }^{95}$. Künstler wie Daumier ${ }^{96}$, Grandville, Traviès und andere verliehen der Bildpublizistik neue Aussagekraft. Richtete das Symbol des Löschhütchens sich während der Julirevolution von 1830 noch gegen die Vertreter der Restauration, so wurde es nun mehr und mehr zum Symbol des neuen Systems, das als Fortsetzung der überwunden geglaubten Verhältnisse empfunden wurde. Grandvilles Lithographie Les Ombres portées zeigt, wie das wahre Gesicht von Vertretern verschiedener gesellschaftlicher Gruppen durch ihre Schatten entlarvt wird ${ }^{97}$. Ein Priester im Ornat und ein Jesuit als Repräsentanten der Geistlichkeit werfen beide den Schatten eines Löschhütchens. Sie stellen sich lediglich zum Schein auf die neuen Verhältnisse ein, ohne sich zu ändern ${ }^{98}$. Dennoch spielte die Kirche in der Julimonarchie kaum eine beherrschende Rolle. Durch ihre starke Bindung an die Bourbonen hatte sich der Antiklerikalismus in weiten Teilen der Bevölkerung durchgesetzt. Dem versuchte die Kirche nach dem Verlust vieler Privilegien unter anderem durch die Zuwendung zu sozialen Problemen entgegenzuwirken ${ }^{99}$. Die durch den politischen Rückzug der Kirche vakant gewordene klerikale Reaktionssymbolik wurde allmählich auf die Julimonarchie übertragen, die schließlich als >neue Religion< karikiert wurde. Grandvilles im Juni 1833 erschienenes Blatt L'Élévation de la poire zeigt, wie der an seinem Klumpfuß zu erkennende Talleyrand vor einem Altar eine lichtstrahlende Birne emporhebt, die von den versammelten Notabeln angebetet wird ${ }^{100}$. Die Form der Birne als viel-

95 Klaus Schrenk, J. J. Grandville - ein französischer Künstler im Spiegel der Julimonarchie, in: J. J. Grandville. Karikatur und Zeichnung. Ein Visionär der französischen Romantik, Ausstellungskatalog, hg. v. d. Staatlichen Kunsthalle Karlsruhe, OstfildernRuit 2000, S. 24f. Zu La Caricature vgl. den Ausstellungskatalog La Caricature. Bildsatire in Frankreich 1830-1835 aus der Sammlung van Kritter, hg. v. d. Universität Göttingen, Göttingen 1980, sowie Susanne Bosch-A beLE, La Caricature (1830-1835), 2 Bde., Göttingen 1997. Zu Le Charivari vgl. allg. Ursula E. Косн, Pierre-Paul Sagave, Le Charivari. Die Geschichte einer Pariser Tageszeitung im Kampf um die Republik (1832-1882). Ein Dokument zum deutsch-französischen Verhältnis, Köln 1984.

96 Die in diesem Kapitel erwähnten Arbeiten von Honoré Daumier sind einsehbar bei daumier-register.org. Graphiken von Daumier werden zudem mit der Nummer des Werkverzeichnisses zitiert: Loys Delteil, Le Peintre-Graveur illustré. XIX $\mathrm{X}^{\mathrm{e}}$ et $\mathrm{XX}^{\mathrm{e}}$ siècles, Bd. 20-29: Honoré Daumier, New York 1969 (Reprint der Ausgabe Paris 1925).

97 La Caricature, 11.11.1830. Eine Woche später wurde ein zweites Blatt unter diesem Titel publiziert. Vgl. dazu J. J. Grandville. Karikatur und Zeichnung, Abb.S.62, S.120f., Kat. 2, sowie FiScher, Wer löscht das Licht, S.128f.

98 Dies zeigt auch die Fortsetzung des Blattes, auf der ein Jesuit die Kokarde angeheftet hat. Vgl. J. J. Grandville. Karikatur und Zeichnung, Abb.S.63, S.121, Kat.3.

99 Tulard, Frankreich, S.382: "Die Julimonarchie bekundete eine tiefe Gleichgültigkeit in religiösen Dingen $\ll$.

100 Erschien im Juni 1833 als elftes Blatt der Association mensuelle: Diese insgesamt 24teilige Karikaturenserie erhielten die Mitglieder der von Philipon gegründeten Association pour la liberté de la presse für den Monatsbeitrag von 1 Franc. Vgl. J. J. Grandville. Karikatur und Zeichnung, S. 191f., Kat. 78 (Abb.S. 192). 
fach variiertes Symbol für Louis-Philippe ${ }^{101}$ wiederholt sich in den Rauchgefäßen ebenso wie in den birnenförmigen éteignoirs, mit denen die Kerzen bereits gelöscht wurden. Alle Agierenden sind Vertreter der Monarchie, vom Juristen bis zum Pair. Eine in den Boden eingelassene Grabplatte verweist auf die Ideale, die >zu Grabe getragen`wurden: »Ici reposent les héros de juillet «. Diese Botschaft wird im Altarbild wiederholt: Die von einem Regenbogen begleitete strahlende Sonne der Trois Glorieuses wird von einer dunklen Wolke überschattet, aus der die Birne hervorragt. Dasselbe Finsternissymbol verwendete Grandville bereits im Oktober $1832^{102}$. Das von Regierungskrisen ins Schwanken gebrachte System, das hier als überfüllter Kahn dargestellt wird, droht zudem an der Klippe der Liberté de la presse aufzulaufen. Der Kampf um das Licht ist zu diesem Zeitpunkt noch nicht entschieden; es scheint möglich, daß die Sonne am Himmel sich gegen die Birne durchsetzen kann, da die dunklen Wolken einen Sturm ankündigen, der dem unsicheren Boot gefährlich werden könnte. Das Altarbild in der Élévation de la poire hat dagegen den Augenblick des Triumphes über das Licht schon als Monument konserviert.

Die rituelle Lichtauslöschung der chevaliers de l'Éteignoir aus der Restaurationszeit wird also insofern modifiziert, als mit der leuchtenden Birne ein Lichtgötze, ein Blendlicht geschaffen wird ${ }^{103}$. Diesem Akt folgt der Kampf gegen das wahre Licht auf dem Fuß: Eine anonyme Graphik von 1834 zeigt den König als Fürsten der Dunkelheit, der die göttliche Lichtschöpfung umkehrt: »Et il dit que le cahos fut. / Et il dit que la lumière était mauvaise, et il éteignit la lumière dans les ténèbres ${ }^{104}$. Eine bedrohliche schwarze Rückenansicht Louis-Philippes verdunkelt mit der klauenartigen Rechten die Sonne des Juli und stülpt mit der linken Hand einen gewaltigen Löschhut über das Licht der Liberté de la presse. Dennoch blieb die Hoffnung auf die Durchsetzung der Pressefreiheit lebendig, wie ein im April 1834 publiziertes Blatt von Grandville und Desperret zeigt ${ }^{105}$. Die personifizierte Freiheit hält in der

101 Zur Entstehung und Entwicklung vgl. Schrenk, Tendenzen, bes. S.152-155 sowie DERS., J. J. Grandville, S. 27.

102 Il ne savent plus à quel saint se vouer, in: La Caricature, 18.10.1832, in: J. J. Grandville. Karikatur und Zeichnung, S. 157f., Kat. 42, Abb. S.157; sowie BosCH-ABELE, La Caricature, Bd. 1, S. 318-320.

103 Das Motiv des Blendlichts bestimmt auch Grandvilles Darstellung eines Feuerwerks zu Ehren von Louis-Philippes Namenstag mit dem Titel Le Bouquet, in: La Caricature, 12.5.1831, in: J. J. Grandville. Karikatur und Zeichnung, S.127f., Kat.11; Bosch-ABELE, La Caricature, Bd. 1, S. 120. Dazu auch Kap.7.1.1.

104 Anonym, Et il dit que le cahos fut./ Et il dit que la lumière était mauvaise, et il éteignit la lumière dans les ténèbres. Lithographie, 1834. Nancy, Bibliothèque nationale. Inv. Nr. Estampes $77865^{43 n}$, in: J. J. Grandville. Karikatur und Zeichnung, S.196f., Kat. 86. Abb. S. 197. (Die Schreibung cahos folgt dem Bildtext.)

105 Soufflez, soufflez, vous ne l'éteindrez jamais! in: La Caricature, 3.4.1832. Dazu ReichardT, Lumières, S. 160, sowie S.161, Abb.45; J. J. Grandville. Karikatur und Zeichnung, S.179f., Kat. 65 . 
erhobenen Rechten eine hell leuchtende Fackel mit der Aufschrift presse, die ihre Gegner erfolglos auszublasen versuchen: "Soufflez, soufflez, vous ne l'éteindrez jamais «! Im Gegensatz zur klerikalen Brandfackel der Restaurationszeit symbolisiert die Fackel hier nun ein mächtiges Licht, das nicht zum Verlöschen gebracht werden kann. Philipons Kommentar droht zudem, daß die Fackel die Angreifer verbrennen werde ${ }^{106}$. Das Licht entbrennt gemäß seiner revolutionären Tradition wiederum zur Waffe gegen die Finsterlinge ${ }^{107}$.

Die Februarrevolution von 1848 und die Gründung der II. Republik schienen diese Hoffnung zu bestätigen. Erst im Juni 1850 aber griff Daumier das Motiv des seine Feinde schlagenden Revolutionslichts auf: Als Les Moucherons politiques umschwirren die Hauptakteure der monarchistisch-katholischen Ordnungspartei das Kerzenlicht der Revolutionstage ${ }^{108}$.

Bei der Wahl zur gesetzgebenden Nationalversammlung im Mai 1849 hatten die Vertreter der Legitimisten, Orléanisten und der Kirche mit 500 Abgeordneten gegenüber nur 75 gemäßigten Republikanern und 210 Radikalen eine deutliche Mehrheit errungen, was nicht zuletzt auf die durch den Juniaufstand von 1848 geschürten Ängste des Bürgertums zurückzuführen war ${ }^{109}$. Der mit toten Mücken übersäte Boden sagt zwar auch den neuen Angreifern ein schlimmes Ende voraus, trotzdem aber hat Daumier ihre Gefährlichkeit nicht unterschätzt: Unter den Lichtfeinden befinden sich auch der Journalist Adolphe Thiers, politischer Karrierist und ehemaliger Ministerpräsident Louis-Philippes ${ }^{110}$ sowie

106 ReichardT, Lumières, S. 160.

107 Mit der Kerzenmetapher gab Desperret 1832 der Hoffnung auf eine europäische Revolution Ausdruck: Das blendende Licht einer überdimensionalen Kerze läßt die umherschwirrenden, winzigen Potentaten abstürzen, nachdem sie vergebens versucht hatten, dem Licht mit Löschhütchen beizukommen: Ils se brûleront tous! Als Kerzenständer dient eine karyatidenartige Frauenfigur, die durch ihre phrygische Mütze als Personifikation der Republik erkennbar ist. Die Verzerrung der Größen- und damit Machtverhältnisse macht deutlich, daß auch das nichtaggressive Kerzenlicht stark genug ist, um ganz Europa zu erhellen. Dadurch rückt die Vision einer Universalrevolution - ähnlich wie 1793 in Le Nouvel Astre français dargestellt - erneut ins Bewußtsein, und zwar sowohl raum- als auch zeitübergreifend: Während Karl X. schon geschlagen ist, geht Louis-Philippe mit den Vertretern seines juste milieu gerade zum Angriff über, doch der Ausgang seiner Löschaktion ist im Futur der Legende bereits vorweggenommen: Alle werden früher oder später an der Überlegenheit des republikanischen Freiheitslichts scheitern. Als Geschöpfe der Finsternis verglühen die Republikfeinde im Licht, als zur Erkenntnis der Wahrheit unfähige, geistige 'Motten ' werden sie davon geblendet. In: La Caricature, 27.9.1832. Abgebildet in: La Caricature. Bildsatire in Frankreich 1830-1835, S.150f., Kat.52; ReICHARDT, Lumières, S.161-163; Fischer, Wer löscht das Licht, S.134-136. Zum Motiv der im Kerzenlicht zugrundegehenden Falter, das in der III. Republik besondere Verbreitung findet, vgl. Kap. 5.2. sowie viele Beispiele in den folgenden Kapiteln.

${ }^{108}$ Le Charivari, 3.6.1850 (D 2012). Dazu ReichardT, Lumières, S. 163; S. 164 Abb. 47 , sowie Fischer, Wer löscht das Licht, S. 137.

$109 \mathrm{Vgl}$. Tulard, Frankreich, S. 459.

110 Zur Person Thiers' ibid., bes. S. 365. 
der Katholikenführer Comte Montalembert ${ }^{111}$, die eine unheilvolle Allianz gegen die Republik bilden. Zwar läßt Daumier sie und ihre Anhänger wenige Tage später als Les Nouveaux Icares unter der sengenden Sonne des février 1848 , der sie mit dem Löschhütchen beikommen wollten, in die Tiefe stürzen ${ }^{112}$, doch auf anderen Darstellungen läßt Daumier die Angreifer subtilere Wege finden: Schon im April 1850 erscheint das Blatt Un parricide, auf dem Thiers die lichtstrahlende Figur der Pressefreiheit hinterrücks mit der Keule restriktiver Pressegesetze überfälltt ${ }^{113}$. All dies ist die Vorbereitung für die längst bezweckte Auslöschung der Revolutionssonne. Am 15. August 1851 zeigt Daumier, wie der auf den Schultern eines Mönchs thronende Montalembert der Sonne selbst mit seinem Löschhut den Garaus machen will: Ils voudraient éteindre jusqu'au Soleil ${ }^{114}$. Daneben stehen die mit Löschhütchen erstickten Kerzen, Symbole der eingeschränkten Pressefreiheit ${ }^{115}$ und der Schulbildung, die seit der loi Falloux von 1850 dem Klerus wiederum großen Einfluß auf die Erziehung ermöglichte ${ }^{116}$. Die Sonne wurde im Kontext der beschnittenen Meinungsfreiheit daher neutralisiert und nicht mehr als Soleil de février gekennzeichnet.

Auf die Rückkehr zur stärkeren Codierung der Karikatur folgte jedoch bald die weitgehende politische Abstinenz. Am 10. Dezember 1851, acht Tage nach Louis-Napoleons Staatsstreich, kündigte Le Charivari an, sich künftig mehr der unpolitischen Gesellschaftssatire widmen zu wollen ${ }^{117}$. Das LichtFinsternis-Thema tauchte infolgedessen nur noch selten und in stark verfremdeten Zusammenhängen auf, was dennoch Schlaglichter auf die politische

111 Besonders die Politik Montalemberts thematisierte Daumier von 1850-1851 als eine Art katholischer Gegenrevolution. Das Löschhütchen ist darin stets präsent - sei es als Waffe oder als Kopfbedeckung, die den konsequenten Kampf gegen die geistige Freiheit symbolisiert. Dazu ausführlich Fischer, Wer löscht das Licht, S.182-190. So stürmt Montalembert mit dem Löschhut in der Hand das Pantheon, um statt der großen Geister die Kapuziner darin einzusetzen, deren sprichwörtliche Kapuzen wie eine ideologische Wiederholung des Löschhütchens wirken und zudem an das Motiv der verhüllten Wahrheit erinnern. Mr. De Montalembert marchant à l'assaut du Panthéon afin d'en chasser les grands hommes pour y installer les capucins, in: Le Charivari, 22.4.1851. Der Auslöschung des Pantheons als Lichttempel folgt bald die Ketzerverbrennung auf dem Scheiterhaufen als un autodafé $d u X I X^{e}$ siècle. Auch hier stehen die dunklen Kapuzenmänner im Hintergrund, als unheilvolle Schatten einer längst überwunden gegelaubten Intoleranz. Un autodafé au $X I X^{e}$ siècle: touchante cérémonie religieuse organisée par les soins des révérends Montalembert et Veuillot, in: Le Charivari, 13.4.1851.

112 Le Charivari, 7.6.1850 (D 2013). Vgl. dazu ReICHARDT, Lumières, S.163 und S.165, Abb. 48.

113 Le Charivari, 16.4.1850 (D 2002).

114 Vgl. dazu Fischer, Wer löscht das Licht, S. 184.

115 Am 16.7.1850 wurde der Zeitungsstempel wiedereingeführt und die Kaution für Tageszeitungen auf 24000 Francs festgesetzt. Am 17.4.1851 wurde Le Charivari erstmals wieder beschlagnahmt. Koch, SAGAVE, Le Charivari, S. 30.

116 Vgl. TulaRd, Frankreich, S. 461.

117 Der übersetzte Wortlaut bei Koch, Sagave, Le Charivari, S.29f. Allg. zur Pressezensur der Jahre 1852-1863 vgl. François CARON, Frankreich im Zeitalter des Imperialismus 1815-1918, Stuttgart 1991, S.36f. 
Situation wirft: Im April 1857 erschienen in Le Charivari zwei Blätter von Daumier, die auf die Hypothese des Physikers Jacques Babinet ${ }^{118}$ reagierten, wonach die Sonne plötzlich und vollständig erlöschen könne. Auf der ersten Darstellung sieht man einige Bürger, die sich in Erwartung dieser Finsternis auch am hellen Tage nur mit Laternen auf die Straße wagen ${ }^{119}$, während das zweite Blatt zeigt, wie Babinets aus einer dunklen Wolke hervorragende Hand der Sonne einen Löschhut aufsetzt, um seine eigene Vorhersage eintreten zu lassen. ${ }^{120}$ Vordergründig korrespondiert das Blatt lediglich mit dem satirischen Kommentar Fin du soleil, den Taxile Delord bereits am 1. April 1857 in Le Charivari veröffentlicht hatte. Delord wirft Babinet vor, sich durch die Verbreitung von Panik in den Vordergrund spielen zu wollen. Daumier zeigt dagegen auf dem ersten Blatt, daß die Ruhe der Bürger offenbar nicht so leicht zu erschüttern ist: Die überhebliche Miene des mit Zylinder und Regenschirm ausgerüsteten Flaneurs zeigt, daß er zu seiner Selbsterleuchtung mittels Handlaterne vollstes Vertrauen hat, auch wenn diese noch gar nicht entzündet ist. Erst als im zweiten Blatt die Sonne wirklich erlöscht bzw. gewaltsam zum Erlöschen gebracht wird, flieht derselbe Mann voll Entsetzen, seine Laterne aber ist nirgends mehr zu sehen. Dieses Blatt korrespondiert nicht zufällig mit der oben erwähnten Karikatur Ils voudraient éteindre jusqu'au soleil. Die wahrgewordene prédiction bezieht sich implizit auf die unheilvolle Entwicklung, die bereits das Blatt aus dem Jahr 1851 vorausgesehen hatte. Eine indifferente Öffentlichkeit, die den Wert der wahren lumières nicht erkennt und nicht verteidigt, wird schließlich zu einem Leben in Dunkelheit verdammt sein. Daumier nützt also eine naturwissenschaftliche Lehrmeinung, um die Erinnerung an den früheren Diskurs wach zu halten und gleichzeitig auf die politische Finsternis im Kaiserreich anzuspielen, die ihren Höhepunkt möglicherweise noch gar nicht erreicht hat. Die törichte Reaktion, sich dem zu fügen, heißt, sich gegen die Sonne und für ein schwaches sekundäres Licht zu entscheiden, ohne die Konsequenzen abschätzen zu können.

Zwei andere Karikaturen von Daumier zum Krieg in China entlarven mit dem Thema der illuminierten >Barbaren dungsbewußtsein, indem sie die scheinbare Unterlegenheit der >Zivilisierungsbedürftigen ` ins Groteske verkehren ${ }^{121}$.

118 (1794-1872), Mitglied der Académie française.

119 Précaution indispensable que prennent les Parisiens lorsqu'ils sortent de chez eux, même en plein midi, depuis qu'ils ont appris par Mr. Babinet que le soleil pouvait s'éteindre d'un moment à l'autre, in: Le Charivari 10.4.1857 (D 2938).

${ }^{120} \mathrm{Mr}$. Babinet se décidant à aller éteindre lui-même le soleil pour ne pas faire mentir sa prédiction, in: Le Charivari 15.4.1857 (D 2939). Dazu kurz FISCHER, Wer löscht das Licht, S.189f., der allerdings den vor der Verfinsterung fliehenden Mann für Babinet hält und dessen Person im unklaren läßt.

121 Dazu Monika Bosse, André Sroll, Zensur und Illumination der Barbaren. Zum semiotischen Prozeß der Diskurskritik Daumiers im Second Empire, in: Raimund RürTEN (Hg.), Die Karikatur zwischen Republik und Zensur. Bildsatire in Frankreich 1830-1880 
Am 7. November 1859 erschien in Le Charivari die Karikatur eines mit Straßenlaternen bewaffneten chinesischen Spähtrupps: Patrouille chinoise en reconnaissance. Die zu wörtlich genommene - mit Papierlampions ausgestattete - chinesische Aufklärungsmission war schon einige Monate vorher Thema eines Blattes von Daumier: Patrouille chinoise mit dem Untertitel: »Guerriers ayant pris trop à la lettre la consigne qu'on leur a donnée d'éclairer la marche de l'ennemi... «122. Die Unterstellung der Europäer, wonach jegliche militärische Taktik den >Barbaren` fremd sei, vereint sich mit dem Motiv des spielerischen Papierlampions zu der rassistischen Verweigerung, den Gegner wenigstens in seinem eigenen Kulturkreis ernst zu nehmen. Wenn schließlich die Lampions durch die moderne Variante der Straßenlaternen ersetzt werden, so führt sich der Witz der ersten Darstellung vollends ad absurdum. Scheinbar versuchen die rückständigen Chinesen nun, dem Gegner mit seinen eigenen - fortschrittlichen - Methoden beizukommen. Daß die ungeschickte Patrouille sich dabei genauso selbst verrät, wie auf der ersten Darstellung, ist nur auf den ersten Blick der Kern des Blatts. Vielmehr tritt die Unmöglichkeit des Transfers selbst in den Vordergrund: Die sentwurzelten $<$ Straßenlaternen können gar nicht funktionieren, weder technisch noch als Symbole der lumières. Als Requisiten des sich selbst rühmenden Fortschritts, der auf diese Weise in die Welt getragen werden will, stehen sie für dessen Ablösung von einem tragfähigen Wertesystem.

Mit der Liberalisierung der kaiserlichen Politik erlebte auch die politische Karikatur eine Renaissance: Die im März 1868 gewährte Pressefreiheit, die allerdings durch die gesetzliche Verfolgung von sogenannten Mißbräuchen eingeschränkt war ${ }^{123}$, zog die Gründung von 140 oft kurzlebigen Zeitungen nach sich ${ }^{124}$. Das im Juni 1868 liberalisierte Versammlungsrecht stärkte die

- eine Sprache des Widerstandes? (Beiträge und Kommentar zum internationalen und interdisziplinären Kolloquium über den satirischen Bildjournalismus im 19. Jahrhundert an der Universität Frankfurt, 24.-27. Mai 1988), Marburg 1991, S.339-341; Christiane BLAss, China: Die List der Belagerten oder wie Daumier mit der >Zivilisation ‘ verfährt, in: André SToLl (Hg.), Die Rückkehr der Barbaren. Europäer und 'Wilde` in der Karikatur Honoré Daumiers, Ausstellungskatalog, Bielefeld 1985, S. 304.

122 Le Charivari, 25.1.1859 (D 3106).

123 Caron, Frankreich im Zeitalter des Imperialismus, S. 199. Dazu Raimund Rütren, Die Agonie, in: Ders. u. a. (Hg.), Die Karikatur zwischen Republik und Zensur, S. 416: »Vieles spricht dafür, daß diese Erleichterungen eine Verschärfung der Zensurmaßnahmen zur Folge hatten: Bis Jahresende wurden gegen die Presse 66 Monate Gefängnis verhängt und 120000 Franken Strafgeld erhoben «.

124 CARON, Frankreich im Zeitalter des Imperialismus, S. 167: Die »stärkste Herausforderung « war Henri Rocheforts am 31. Mai 1868 erstmals erschienene Zeitung La Lanterne, das erste "satirische Journal mit leicht diffamierender Tendenz«. Nach der 11. Ausgabe wurde La Lanterne verboten, aber eine Zeitlang von Belgien aus eingeschmuggelt. Die Lichtsymbolik des Titels nahm André Gill in der L'Éclipse auf: Er stellte Rochefort als Don Quichote dar, der die Finsternis mit einer Laterne durchdringen will. FIScher, Wer löscht das Licht, S. 80, Abb. 125. 
republikanische Opposition, die 1869 die Mehrheit im Parlament errang ${ }^{125}$. Daumier schien diesen neuen Freiheiten zunächst nicht zu trauen, wie sein Blatt Lanterne magique!!! zeigt, veröffentlicht im Charivari am 19. November 1869126. Die Allegorie der France projiziert mittels einer Laterna Magica mit der Bezeichnung scrutin das Wort liberté an die schwarze Wand. Ob der helle Lichtschein eher illusorischen Charakter hat oder auf eine >lichte< Zukunft verweist ${ }^{127}$ - für den 29 . November hatte Napoleon III. die Einberufung der verfassunggebenden Versammlung angekündigt ${ }^{128}$-, bleibt unklar. Die Reformen, die unter anderem einen Verzicht auf offizielle Regierungskandidaten bei Wahlen betrafen, würdigte Daumier in der Darstellung Gare la lumière! ${ }^{129}$, in der die Laterne der Liberté électorale ihre eulenartigen Gegner blendet. Auffallend aber ist, daß Daumier für das liberale Kaiserreich nur künstliche Lichtquellen verwendete, deren Dauerhaftigkeit dahingestellt bleibt. Zwar karikiert er die vergeblichen Bemühungen des Vatikanischen Konzils, die hell lodernde Fackel der Libre Pensée auszublasen ${ }^{130}$, doch die Sonne der Freiheit läßt er zunächst nur als zaghaften Sonnenaufgang am Horizont erscheinen: Die Allegorie der France führt einen zaudernden Mann zu diesem noch fernen Licht und beruhigt ihn angesichts einer Vogelscheuche mit der Bezeichnung spectre rouge mit den Worten: "Ne regardez donc pas par là, vous voyez bien que c'est un mannequin «131. Der Weg in die Freiheit führt demnach an der Überwindung der Angst vor einer sozialistischen Prägung der Gesellschaft vorbei. Gleichzeitig impliziert das Blatt die immanente Furcht einer lieber ins Dunkel blickenden Gesellschaft vor der Freiheit selbst: Das Licht scheint noch ungewohnt; die Sonne der Republik ist noch nicht aufgegangen.

125 Rütten, Die Agonie, S. 419.

126 (D 3745). Dazu ausführlich LE MEN, Lanterne magique!!!

127 Als Aufklärungsinstrument erscheint die Laterna magica bereits in der Revolution. Vgl. Vovelle, Image et récit, Bd.3, S.41: Die um 1791 entstandene Darstellung La lanterne magique zeigt, wie den europäischen Monarchen der Fall des Ancien Régime als allegorische Laterna-Magica-Projektion vor Augen geführt wird. Das Lichtbild erhält so die Qualität einer technisierten Schreckensvision. Die Laterna Magica leistet also tatsächlich ,Aufklärunge. Vgl. auch Jean-Jacques TATIN-GouriER, Lanterne et Révolution, in: Ségolène Le Men (Hg.), Lanternes magiques, tableaux transparents, Ausstellungskatalog, Paris, S.101f. Zur Kulturgeschichte vgl. Ulrike Hick, Geschichte der optischen Medien, München 1999, bes. S.131f.; Blühm, LippincotTr, Light, S.50, S.220; David Robinson, The Lantern Image. Iconography of the Magic Lantern 1420-1880, London 1993.

128 Caron, Frankreich im Zeitalter des Imperialismus, S. 203.

129 Le Charivari, 5.4.1870 (D 3776).

130 Répétition générale du concile, in: Le Charivari, 27.10 .1869 (D 3744).

131 Le Charivari, 9.12.1869 (D 3752). 
